\title{
Summer Rainfall Anomalies in the Yangtze Valley and the Middle Reaches of the Yellow River in China and Their Association with the Atmospheric-Oceanic Circulation Indices from 1951 to 1991
}

\author{
Zhenhao Bao and Takehiko Mikami \\ Department of Geography, Tokyo Metropolitan University, Hachioji, \\ Tokyo 192-0397, Japan
}

\begin{abstract}
High negative correlation between summer rainfall anomaly in the Yangtze Valley and the middle reaches of the Yellow River in China is shown. Rainfall Anomaly Index (RAI) and the Student's t-test revealed a decadal fluctuation of RAI in the Yangtze Valley at the end of the 1970s. The results concerning correlation between RAI and atmospheric circulation indices show that the variation of summer RAI in the Yangtze Valley is closely related to western Pacific subtropical high index $\left(20-30^{\circ} \mathrm{N}, 130-170^{\circ} \mathrm{E}\right)$ at $500 \mathrm{hPa}$-level in May and westerly zonal index $\left(40-60^{\circ} \mathrm{N}, 90-170^{\circ} \mathrm{E}\right)$ at $500 \mathrm{hPa}-$ level in July. The decadal fluctuation of RAI at the end of the 1970s in the Yangtze Valley corresponds to the fluctuation of westerly zonal index in July and western Pacific subtropical high index in May. The impact of sea surface temperature (SST) $\left(\mathrm{EQ}-14^{\circ} \mathrm{N}, 130-150^{\circ} \mathrm{E}\right)$ in the western Pacific Ocean on RAI in the Yangtze Valley is also discussed. The negative correlation between the SST in June and summer RAI in the Yangtze River at the end of 1970s exhibits a clear atmospheric-oceanic teleconnection. It is closely associated with rainy conditions in the Yangtze Valley during El Niño in the period 1978-1991.
\end{abstract}

Key words: PCA, summer rainfall anomaly, the Yangtze Valley, atmospheric-oceanic circulation indices, interannual and decadal variation

\section{Introduction}

Many studies have been made to investigate rainfall variation in China (e.g., Wang and Zhao 1981; Ding 1994; Yatagai and Yasunari 1994, 1995; Nitta and $\mathrm{Hu}$ 1996). In these studies, summer rainfall data was used as a dependent variable to analyze rainfall characteristics. Wang and Zhao (1981) used rainfall data (19511974 ) in order to investigate the spatial pattern in China. Nitta and $\mathrm{Hu}$ (1996) analyzed the spatial and temporal characteristics of rainfall in China with canonical spatial field of extended Empirical Orthogonal Function (EOF) in rainfall data for 1951-1994. Tian and Yasunari (1992) revealed the seesaw pattern between the Yangtze Valley and the northern part of China using the reconstructed series of the 2-4 year component in May-September from 1951 to 1990. Simmonds et al. (1996) used the summer precipitation data in China to analyze the relationship between rainfall and sea surface temperature (SST) in two typical areas in the western Pacific Ocean in summer. They considered that the influence of summer SST in the western Pacific Ocean on the summer rainfall in China is more important than the SST over other areas such as eastern Pacific Ocean. These studies showed remarkable variation of summer rainfall in the Yangtze Valley in China. From the statistics for summer rainfall from 1980 to 1989 , it can be seen that heavy summer rainfall prevailed in the Yangtze Valley. Further study is required for clarifying the association between the variation of some atmospheric-oceanic circulation and the summer rainfall in the Yangtze Valley. For instance, the regional rainfall in the Yangtze Valley should be analyzed in comparison with the changes of atmospheric circulation in middle and high latitude and the sea surface 
temperature (SST) in the tropical Pacific Ocean since the middle and end of 1970 s.

While studying regional and temporal rainfall variability, it is necessary to clearly define the regional rainfall ranges. In other words, for a spatially similar group of stations, a time series data of regional rainfall, instead of individual station data, could be used for studying regional and temporal rainfall variability. Identification of homogeneous domains (regionalization) can be attempted with rainfall data on different time-scales, such as months, seasons and years. The criterion used for defining the regions is based on a variety of measurements, such as average values and correlation coefficients. Thus, any regionalization should be at least based on inter-station correlations. The approach of studying and establishing homogeneous domains for rainfall has received considerable attention in the recent meteorological literatures (e.g., Nicholson 1986; Kulkarmi et al. 1992). The EOF analyses have been used for investigating specific anomaly patterns of precipitation. Although EOF indicates the existing regional contrasts of rainfall, a statistical test to verify the significance is not part of the method. Buell $(1975,1979)$ has shown that different correlation functions on a geometrically shaped domain have similar EOF patterns. Principal Component Analysis (PCA) is a well-known multivariate statistical technique that has been used extensively in investigating temporal series of rainfall with significance in different areas (e.g., Horel 1984; Mills et al. 1994). Richman $(1981,1986)$ considered that the weights (known as loadings) in PCA represent the correlations (covariances) between each variable and each principal component. The regional rainfall variation can be better represented using the PCA. Moreover, the temporal signatures of the significant principal components help to arrange stations in relation to their connection with these signatures (e.g., Ehrendorfer 1987; Iyengar et al.1994). Iyengar et al. (1994) classified various precipitation patterns using PCA in Indian monsoon precipitation. Mills et al. (1995) also used the PCA to divide different rainfall patterns in Spain.

In this study, PCA has been selected to define the range of regions for the Yangtze Valley and the middle reaches of the Yellow River. Basical$1 y$, the present study attempts to investigate the regional characteristics of summer rainfall in the Yangtze Valley and the middle reaches of the Yellow River from 1951 to 1991. Moreover, using Rainfall Anomaly Index (RAI) discussed by Katz et al. (1986), the fluctuation of RAI in the regions will be investigated in relation to some atmospheric-oceanic circulation indices. The influence of ENSO on summer rainfall anomaly will also be studied.

\section{Data and Analysis Technique}

\section{Summer rainfall anomaly index}

Summer (June, July and August) rainfall data in China for 41 years (1951-1991) were compiled at 160 stations for the study area based on the available records provided by the Climate Center of China Meteorology Agency. PCA which has been applied to standardized spatial data, so-called S-mode decomposition, can represent variance that is either unique or common (Richman 1981, 1986). The temporal series of PCA-1 and its spatial loading were depicted in Fig. 1a. According to the correlations among the temporal series of PCA-1 (see Fig. 1b) and standardized rainfall departure data in 160 stations, 49 stations in which their coefficients are significant at $98 \%$ level have been organized into the regions lain in the main parts of the spatial loading of PCA-1. Considering the geographical location and representation of the climatic division, out of 49 stations, 25 stations positively related to the temporal series of PCA1 are located in the Yangtze Valley and 11 stations having negative relation are located in the middle reaches of the Yellow River. Moreover, the distribution of the other 13 stations cannot constitute representing regions. Figure 2 shows station distributions in the Yangtze Valley (25 stations) and the middle reaches of the Yellow River (11 stations).

The homogeneous characteristics of rainfall for the Yangtze Valley and the middle reaches of the Yellow River are necessary to identify regional rainfall characteristics. Based on the expressions for examining regional homogeneous characteristics (Kraus 1977), the regional 
(a)

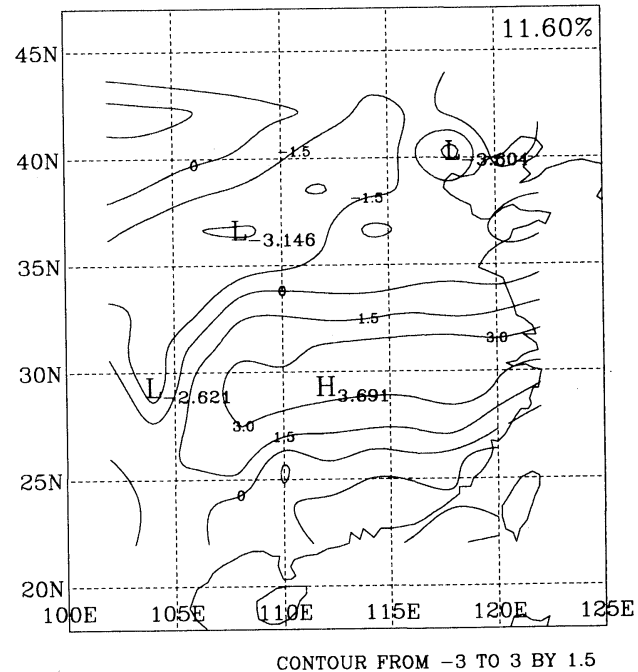

(b)

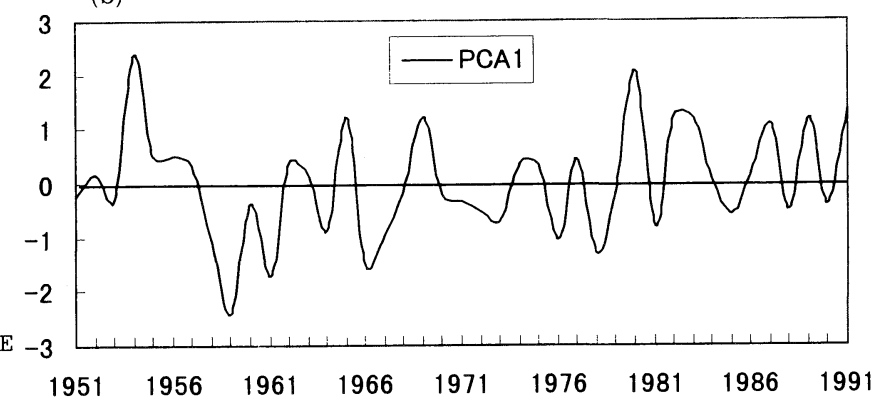

Figure 1. (a) The first eigenvector of normalized summer rainfall departure from 1951 to 1991 (loading is multiplied by 100.) (b) Principal component amplitudes of the first eigenvector of normalized summer rainfall departure from 1951 to 1991.

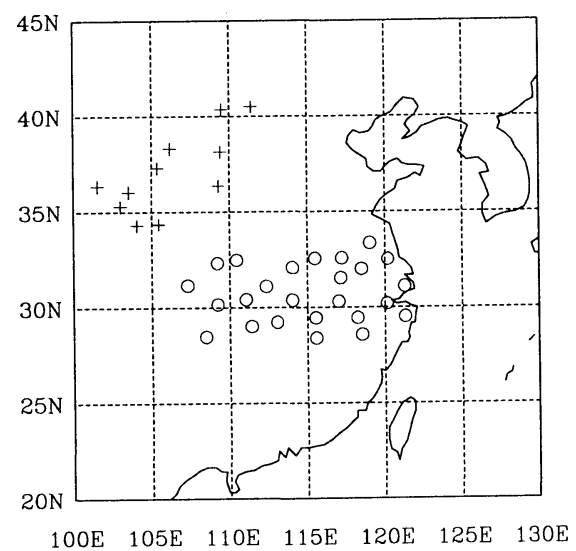

Figure 2. The station distributions in the Yangtze Valley and the middle reaches of the Yellow River.

Circle sign indicates the stations in the Yangtze Valley and plus sign indicates the middle reaches of the Yellow River. homogeneous conditions in the Yangtze Valley and the middle reaches of the Yellow River have significant level (see Table 1). For example, the spatial and temporal ratio in the Yangtze Valley is 16.83 which is much larger than the significant level of F-test at 99\% (1.61). RAI (Rainfall Anomaly Index) (Kraus 1977; Kazt et al. 1986) was used for analyzing the characteristics of summer rainfall in the Yangtze Valley and the middle reaches of the Yellow River. The formula of RAI can be written as

$$
I_{t}=\frac{1}{N} \sum_{i=1}^{N}\left(R_{i t}-\mu_{i}\right) / \sigma_{i}
$$

Here variable $R_{i t}$ denotes the precipitation during the $t$-th time period at the $i$-th station, and the parameters $\mu_{i}$ and $\sigma_{i}$ denote the population means and standard deviations, respective1y. Equation (1)-a can be re-expressed as

$$
I_{t}=\frac{1}{N} \sum_{i=1}^{N} w_{i} R_{i t}-c
$$

Table 1. The regional coherence characteristics in the Yangtze Valley (A1) and the middle reaches of

\begin{tabular}{|c|c|c|c|c|c|c|}
\hline \multirow{2}{*}{ Field } & \multicolumn{3}{|c|}{ Variances } & \multicolumn{2}{|c|}{ Degree of Freedom } & \multirow{2}{*}{$\begin{array}{c}\text { The } F \text { significant level } \\
\text { at } 0.01\end{array}$} \\
\hline & $\mathrm{V}$ (time) & $\mathrm{V}$ (area) & $\operatorname{Ratio}(\mathrm{V}(\mathrm{t}) / \mathrm{V}(\mathrm{a}))$ & $\mathrm{J}-1$ (time) & N-J (area) & \\
\hline A 1 & 10.41 & 0.62 & 16.83 & 40 & 1025 & 1.61 \\
\hline A2 & 5.86 & 0.53 & 11.10 & 40 & 451 & 1.63 \\
\hline
\end{tabular}
the Yellow River (A2) on the basis of expressions by Kraus (1977) 
where $w_{i}=1 / \sigma_{i}$ and $c$ is a constant involving the number of stations $N$, the population means $\left(\mu_{i}\right)$ and the population standard deviations $\left(\sigma_{i}\right)$. The index $I_{t}$ can be viewed as a weighted average of the rainfall for the $N$ stations.

\section{Atmospheric and oceanic circulation indices}

(a) Monthly Subtropical High Index (SUBHI) in the region $20-30^{\circ} \mathrm{N}, 130-170^{\circ} \mathrm{E}$, which indicates subtropical high index (height departure) in the western Pacific Ocean at $500 \mathrm{hPa}$-level.

(b) Monthly Zonal Index (R2-ZI) in the region $40-60^{\circ} \mathrm{N}, \quad 90-170^{\circ} \mathrm{E}$, which indicates westerly flow index (height departure) in East Asia at $500 \mathrm{hPa}$-level.

(c) Monthly Sea Surface Temperature (SST) index in the region $\mathrm{EQ}-14^{\circ} \mathrm{N}, 130-150^{\circ} \mathrm{E}$, which indicates the SST departure in the tropical western Pacific Ocean.

These data were obtained from the records available in Monthly Report on Climate System published by Japan Meteorological Agency (1991, 1992).

\section{Statistical analysis}

The Student's t-test has been used to examine the decadal scale variability of RAI in the Yangtze Valley and the middle reaches of the Yellow River from 1951 to 1991 . The method has been widely used in the analysis for the fluctuation of temperature and precipitation (Karl and Riwbsame 1984; Wei an Chao 1995). The t-test equation can be written as:

$$
t=\left(X_{1}-X_{2}\right) /\left(S_{\mathrm{P}}(1 / m+1 / n)^{1 / 2}\right)
$$

where, $S_{\mathrm{p}}^{2}=\left((m-1) S_{\mathrm{m}}^{2}+(n-1) S_{\mathrm{n}}^{2}\right) /(m+n-2), X_{1}$ and $S_{\mathrm{m}}$ are the sample means and standard deviations over the time span covering $m$ years before abrupt change point respectively; $X_{2}$ and $S_{\mathrm{n}}$ are the same as $X_{1}$ and $S_{\mathrm{m}}$ but after the abrupt change point covering $n$ years. $m$ and $n$ are the sample size of spans before and after the change point, and $S_{\mathrm{p}}$ is the simultaneous sample variance. In this study, the span $m$ and $n$ are the same, that is, the number of years in each of the comparative epochs is equal and the span is taken as 10-15 year duration, which represents decadal scale. The fluctuation index $t$ reflects the decadal variation of rainfall anomaly index.

\section{The Summer Rainfall Anomaly Characteristics in the Yangtze Valley and the Middle Reaches of the Yellow River in Relation to El Niño/Southern Oscillation}

The summer rainfall in various climatic regimes in China has different characteristics. The Meiyu (Baiu) rainfall (from mid-June to mid-July) plays a major role in the distribution of summer precipitation over the Yangtze Valley. This rainy season is characterized by the abundant precipitation and high relative humidity. The rainy season in the middle reaches of the Yellow River starts in the middle-end of July. July and August are two months with frequent occurrences of heavy rainfall in this region.

The summer RAI in the Yangtze Valley and the middle reaches of the Yellow River show a closely negative relationship from 1951 to 1991, and the correlation coefficient in between RAI of the two regions is -0.44 at the significant level of $99 \%$. Comparing RAI in the Yangtze Valley and the middle reaches of the Yellow River before 1958 , it is found that there was apparent positive correlation between RAI of the two regions from 1951 to 1957 . Out of 7 years, the sign of RAI in the two regions in 6 years is corresponding except for 1955 . In the period 1958-1991, the negative correlation between RAI in the Yangtze Valley and that in the middle reaches of the Yellow River is very clear and their correlation coefficient is -0.62 at the significant level of $99.9 \%(0.54)$. The transition from positive correlation in the period 1951-57 to negative correlation in the period 1958-91 is corresponding to the period of strong East Asian monsoon in the late 1950s to the early 1960s (Guo 1988). Chen (1992) clarified that there exist apparent oscillations of periods of 2-3 years and quasi-5-7 years for the East Asia monsoon. In order to explore the impacts of short-term and long-term rainfall fluctuations on the negative correlation in between RAI of the two regions, we use simple moving average such as 3-year, 5-year, 7-year 9year and 11-year for removing different shortterm fluctuations. For example, 9-year moving 
average effectively removes fluctuations shorter than about one decade. The result indicated that the significant level for negative correlation in between RAI of the Yangtze Valley and the middle reaches of the Yellow River is apparently weakened by taking moving averages over 5 years such as 7-year, 9year and 11-year. As for RAI in the Yangtze Valley and the middle reaches of the Yellow River by 3 -year and 5 -year moving average, their correlation coefficients are -0.41 and -0.32 respectively. As for RAI in the two regions by 7 -year, 9 -year and 11-year moving average, their correlation coefficients are $-0.10,0.10$ and 0.11 . The correlation for the case of over 5 -year moving average is much lower than significant level of $95 \%$. In some degrees, short-term fluctuations for the negative correlation between RAI in the Yangtze Valley and the middle reaches of the Yellow River are very important. Removing shortterm fluctuations for summer RAI will weaken their negative correlation in the two regions.

Furthermore, many attempts have been made to analyze summer RAI in association with the dry spells of regional rainfall in the Yangtze Valley and the middle reaches of the Yellow River. At this stage, firstly, the dryness station number in the two regions was selected on the condition of the standardized rainfall departure in each station lower than zero. The distribution of drought/flood from 1951 to 1991 in the two regions is shown in Fig. 3. The analysis also illustrates that the correlation coefficient of (a)

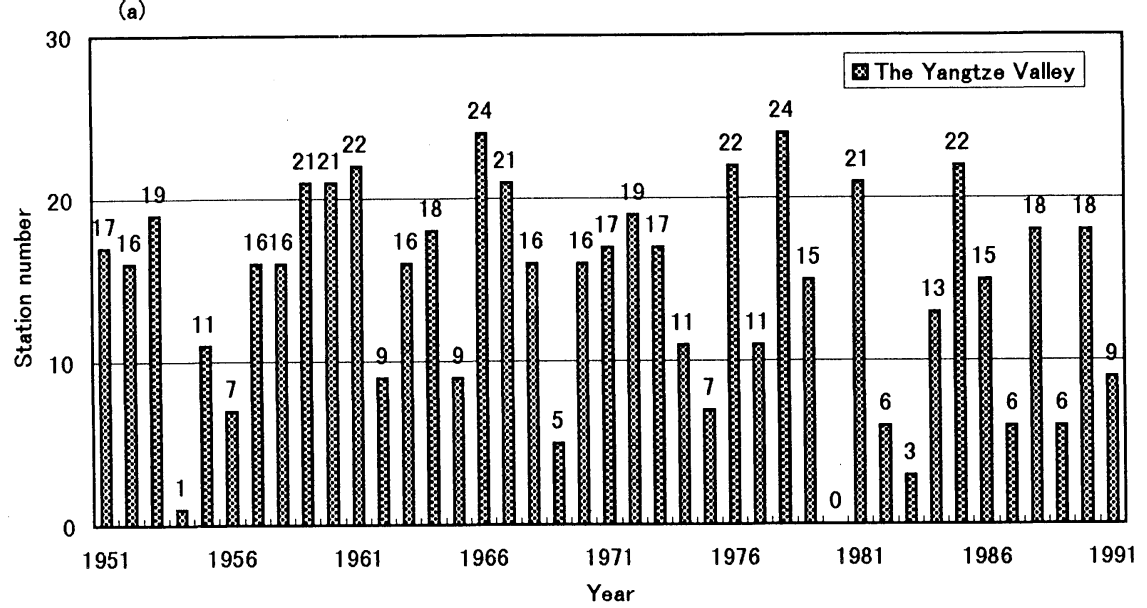

(b)

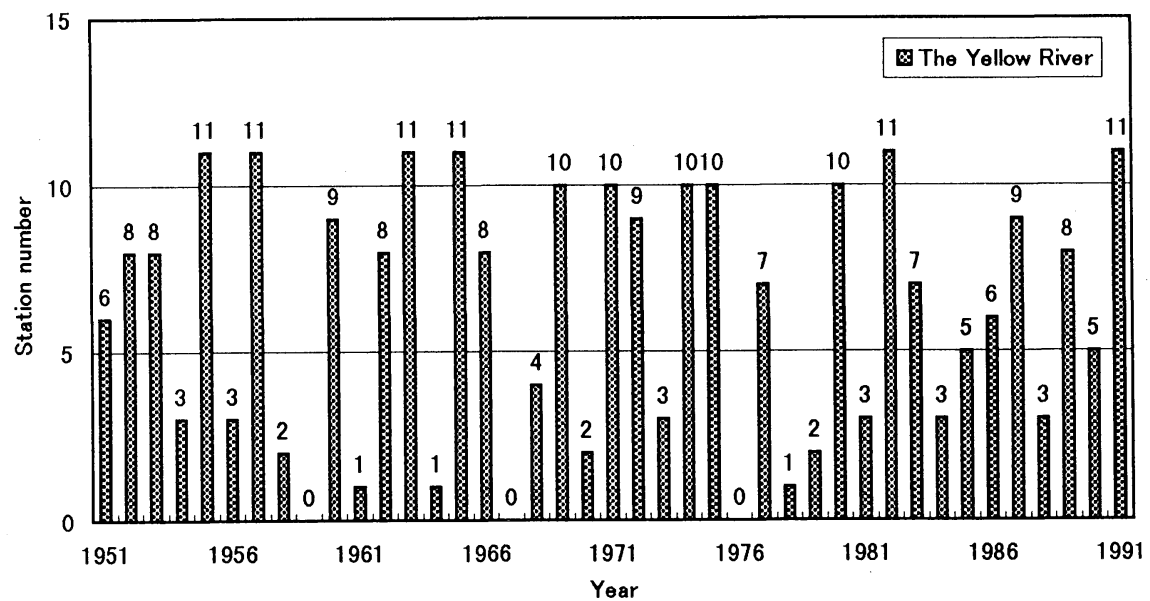

Figure 3. The annual change of dryness (rainfall departure is lower than zero) station numbers (a) in the Yangtze Valley (Total stations is 25) and (b) in the middle reaches of the Yellow River (Total station is 11). 
RAI in the Yangtze Valley and the middle reaches of the Yellow River with the dryness station number in the two regions was -0.95 and -0.95 , respectively. Thus, the high correlation accounting for regional dryness/wetness change can be represented by RAI.

Recent studies show that the annual dry condition in the semiarid area of the middle and upper reaches of the Yellow River is associated with El Niño events in the period 1951-1986 (Wang and Li 1990). Wang and Li (1990) used the monthly individual rainfall data and monthly SOI data to analyze the relationship of individual rainfall in the semiarid regions of the Yellow River with SOI by power spectrum. In the present study, the middle reaches of the Yellow River is partly included in the semiarid area of the Yellow River. Here, we will focus on regional rainfall in the middle reaches of the Yellow River rather than individual rainfall to discuss them in association with ENSO. According to Quinn et al. (1987), Wang (1994) and Guetter (1996), the onset and persistence of El Niño vary significantly for its different episodes. It is identified that dry condition appeared in the middle reaches of the Yellow River during the occurrence of El Niño (see Table 2). The negative RAI in the middle reaches of the Yellow River in 1965 and 1982 is the most apparent case. When we compare the RAI variation in the Yangtze Valley since the end of the 1970's during the El Niño or La Niño event, it is observed that the positive RAI in the Yangtze Valley is corresponding to El Niño event such as 1982,1983, 1987 and 1991. Their percentage of wetness (defined as standardized rainfall departure higher than zero) stations in the region amounts to $76 \%, 88 \%, 76 \%$ and $68 \%$, respectively. Besides, the percentage of dryness stations is $72 \%$ in the La-Niña year 1988. Therefore, wet conditions occurring in the Yangtze Valley in recent 10 years during the onset of El Niño year should be noticed.

Furthermore, SST in the equatorial western Pacific Ocean (EQ- $14^{\circ} \mathrm{N}, 130-150^{\circ} \mathrm{E}$ ) is used for investigating the impacts of SST on summer rainfall in the Yangtze Valley, particularly after 1977. The correlation coefficient between RAI in the Yangtze Valley and the SST in June during $1978-91$ is -0.64 at the significant level
Table 2. RAI in the middle reaches of the Yellow River during the El-Niño Year and La-Niña year. DS: dryness station number every year. TS: total station number in the region is 11

El-Niño

\begin{tabular}{|c|c|c|}
\hline Year & RAI & $\mathrm{DS} / \mathrm{TS}$ \\
\hline 1953 & -0.17 & $72.7 \%$ \\
\hline 1957 & -0.68 & $100.0 \%$ \\
\hline 1963 & -0.68 & $100.0 \%$ \\
\hline 1965 & -1.35 & $100.0 \%$ \\
\hline 1969 & -0.72 & $90.9 \%$ \\
\hline 1972 & -0.41 & $90.9 \%$ \\
\hline 1977 & -0.11 & $63.6 \%$ \\
\hline 1982 & -1.08 & $100.0 \%$ \\
\hline 1983 & -0.24 & $63.6 \%$ \\
\hline 1987 & -0.58 & $90.9 \%$ \\
\hline 1991 & -0.96 & $100.0 \%$ \\
\hline Average & -0.63 & $88.4 \%$ \\
\hline \multicolumn{3}{|l|}{ La-Niña } \\
\hline 1956 & 0.73 & $27.3 \%$ \\
\hline 1964 & 0.88 & $9.1 \%$ \\
\hline 1970 & 0.51 & $18.2 \%$ \\
\hline 1971 & -0.77 & $90.9 \%$ \\
\hline 1973 & 0.43 & $27.3 \%$ \\
\hline 1975 & -0.33 & $90.9 \%$ \\
\hline 1988 & 0.88 & $27.3 \%$ \\
\hline Average & 0.33 & $41.6 \%$ \\
\hline
\end{tabular}

of $95 \%$ (0.53). In the period 1951-77, their correlation coefficient was 0.06 which is much lower than the significant level of $95 \%$.

The physical mechanisms linking the annual rainfall in East Asia and ENSO were explained in detail in Fu et al. (1986). He considered that the impact of SST in the eastern Pacific Ocean on the summer rainfall in Asian monsoon regions is realized by the adjustment of the western Pacific subtropical high which leads the summer monsoon to change. For example, when the equatorial eastern Pacific SST warms (more than normal) in winter during the El Niño year, the location of the subtropical high shifts westward in the next summer. In addition to this, when the western Pacific subtropical high moves further west, it will tend to decrease the extent of the northward movement of the rainfall belt, and will result in a decrease of rainfall in the Yellow River. On the other hand, the variation of RAI in the Yangtze 
Valley is associated with SST in the western Pacific Ocean in June after 1977. The SST in the western Pacific Ocean during El Niño year is below the normal, and it may result in the increase of summer rainfall.

\section{Annual and Decadal Changes of Summer Rainfall Anomaly and Their Associations with Atmospheric-Oceanic Circulation}

Figure 4a depicts the variability of RAI in the Yangtze Valley from 1951 to 1991, and the short dashed horizontal lines represent the means of two comparative epochs with a jump in the Yangtze Valley in the end of 1970's. In the Yangtze Valley, there is an obvious increase of rainfall departure of 13-year epoch of 197991 as compared to the 13-year epoch of 196678. The fluctuation of summer rainfall with decadal scale in the middle reaches of the Yellow River in two epochs before and after the end of 1970s had no significant change (see Fig. $4 \mathrm{~b})$. Although there is a close negative correlation between RAI in the Yangtze Valley and that in the middle reaches of the Yellow River, it is different for their decadal changes.

In the following part, we will discuss the summer rainfall anomaly in the Yangtze Valley and the middle reaches of the Yellow River associated with atmospheric and oceanic circulation in recent 41 years (1951-91).

Ding (1994) considered that the summer monsoon is the most important control for total rainfall in China. In general, there will be less rainfall during Meiyu (Baiu) in the Yangtze Valley if the proceeding summer monsoon is stronger. By contrast, in the weak monsoon year, the Meiyu front will stagnate in the Yangtze Valley for a long time and cause heavy rainfall. For instance, the stronger East Asia summer monsoons during Meiyu in 1958 and 1978 were accompanied by drought in the Yangtze Valley and flood in the middle reaches of the Yellow River.

The East Asian summer monsoon is influenced by the western Pacific Ocean subtropical high and the westerly flow in mid-high latitude. In fact, the subtropical high over the western
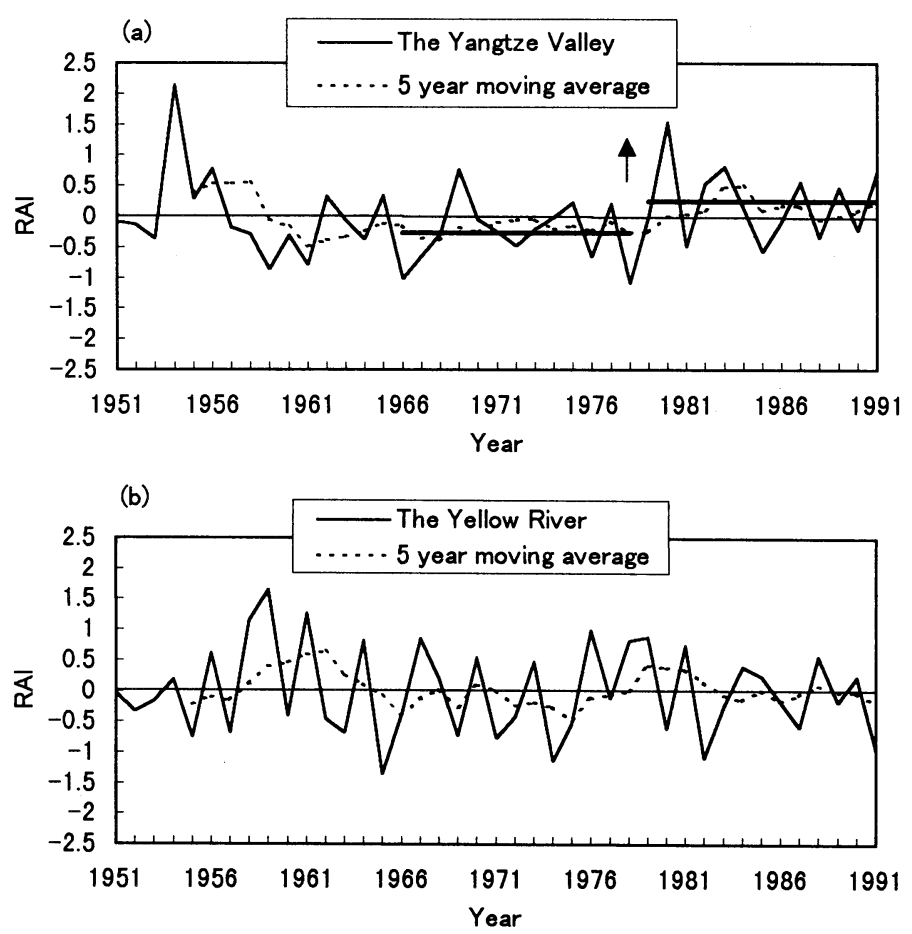

Figure 4. The annual change of RAI from 1951 to 1991 (a) in the Yangtze Valley and a summer RAI fluctuation of increasing from 1966-78 to 1979-91 in the region; and (b) in the middle reaches of the Yellow River. 
Pacific Ocean is very important in controlling summer rainfall in China. Any abnormal variation of this subtropical high will directly influence the rainfall variation of Meiyu in the Yangtze Valley. In this study, the monthly subtropical high index (SUBHI) in the western Pacific and the westerly flow index (R2-ZI) are used in connection with the summer RAI in the Yangtze Valley and the middle reaches of the Yellow River. The SUBHI in the western Pacific Ocean and the R2-ZI in the westerly flow indicate the average height departure at $500 \mathrm{hPa}$ level in the region ranging over $20-30^{\circ} \mathrm{N}, 130-$ $170^{\circ} \mathrm{E}$ and over $40-60^{\circ} \mathrm{N}, 90-170^{\circ} \mathrm{E}$, respectively.

Table $3 \mathrm{a}$ shows that the correlation coefficient between the summer RAI in the Yangtze Valley and westerly flow index (R2-ZI) in July was -0.56 at the significant level of $99.9 \%$. Relatively speaking, the correlation coefficient between summer RAI and R2-ZI in August was lower than that in July. As for the correlation of summer rainfall in the middle reaches of the Yellow River with R2-ZI in July, the correlation coefficient reaches 0.27 which is significant at the level of $90 \%$ (0.26). The association of RAI in the Yangzte Valley and the middle reaches of the Yellow River with the R2-ZI in July shows that the westerly flow index in July is an important factor for their negative correlation in the two regions. Zhang et al. (1986) and Ding (1992) demonstrated that a persistent flow pattern at the middle and high latitudes over Eurasia was characterized by the blocking situation for upstream $\left(90^{\circ} \mathrm{E}\right)$ and downstream $\left(150^{\circ} \mathrm{E}\right)$ of Meiyu (Baiu) region at $50-70^{\circ} \mathrm{N}$ and by the nearly zonal flow prevailing in the latitude band of $35-$ $50^{\circ} \mathrm{N}$. The short-wave troughs in the westerly flow often move southeastward to the Yangtze Valley, bringing cold air over the region and causeing heavy rainfall. The negative R2-ZI in July means that the short-wave troughs in the westerly flow are active and they provide a possibly beneficial situation by inducing more rainfall in the Yangtze Valley. For example, the heavy summer rainfall such as in 1954, 1956, 1980 and 1991 corresponds to highly negative R2-ZI standardized in July for $-1.82,-1.02$, -0.95 and -2.22 , respectively. On the other hand, the strong drought in the Yangtze Valley such as in 1961, 1966 and 1978 are corresponding to highly positive R2-ZI standardized in July for $1.50,1.14$ and 2.51, respectively (see Fig. 4a and Fig. 5b).

The subtropical high index (SUBHI) in the western Pacific is also an important factor influencing summer rainfall in the Yangtze Valley. The correlation analysis suggests that there is an association of summer rainfall in the Yangtze Valley with the SUBHI in May, and their correlation coefficient is 0.44 at significant level of $99 \%$ (see Table $3 \mathrm{~b}$ ). There are other indices describing the variation of subtropical high in the western Pacific Ocean. Ding (1994) considered that the intensity of subtropical high is generally characterized by its area and the intensity indices. The former is defined as the total number of grid points that have geopotental heights of 588 decameters or greater in the region of $110-180^{\circ} \mathrm{E}$, poleward of $10^{\circ} \mathrm{N}$. Thus, it describes the regional extent of the subtropical high. The latter is defined as the accumulative sum of the geopotential height equal to or greater than 588 decameters in the region of $110-180^{\circ} \mathrm{E}$, poleward of $10^{\circ} \mathrm{N}$.

Table 3. The correlation analysis among RAI in the two regions and monthly R2-ZI (3.a) and monthly SUBHI (3.b) from 1951 to 1991. A1: the Yangtze Valley, A2: the middle reaches of the Yellow River (Significant level of t-test at $95 \%$ is 0.31 and 0.40 , respectively)

3a

\begin{tabular}{ccccccccrrrrr}
\hline Month & 1 & 2 & 3 & 4 & 5 & 6 & 7 & 8 & 9 & 10 & 11 & 12 \\
\hline A1 & -0.06 & -0.13 & 0.20 & 0.01 & 0.19 & -0.13 & -0.56 & -0.36 & 0.04 & -0.04 & 0.06 & -0.28 \\
A2 & 0.14 & 0.08 & -0.01 & 0.13 & -0.07 & -0.03 & 0.27 & 0.11 & -0.05 & -0.06 & -0.26 & -0.10 \\
\hline 3b & & & & & & & & & & & & \\
\hline Month & 1 & 2 & 3 & 4 & 5 & 6 & 7 & 8 & 9 & 10 & 11 & 12 \\
\hline A1 & -0.14 & -0.21 & 0.09 & 0.10 & 0.44 & 0.14 & 0.15 & -0.06 & 0.04 & -0.17 & 0.03 & -0.26 \\
A2 & 0.29 & 0.30 & 0.18 & 0.23 & -0.21 & -0.24 & -0.22 & 0.02 & -0.12 & 0.01 & -0.15 & -0.27 \\
\hline
\end{tabular}



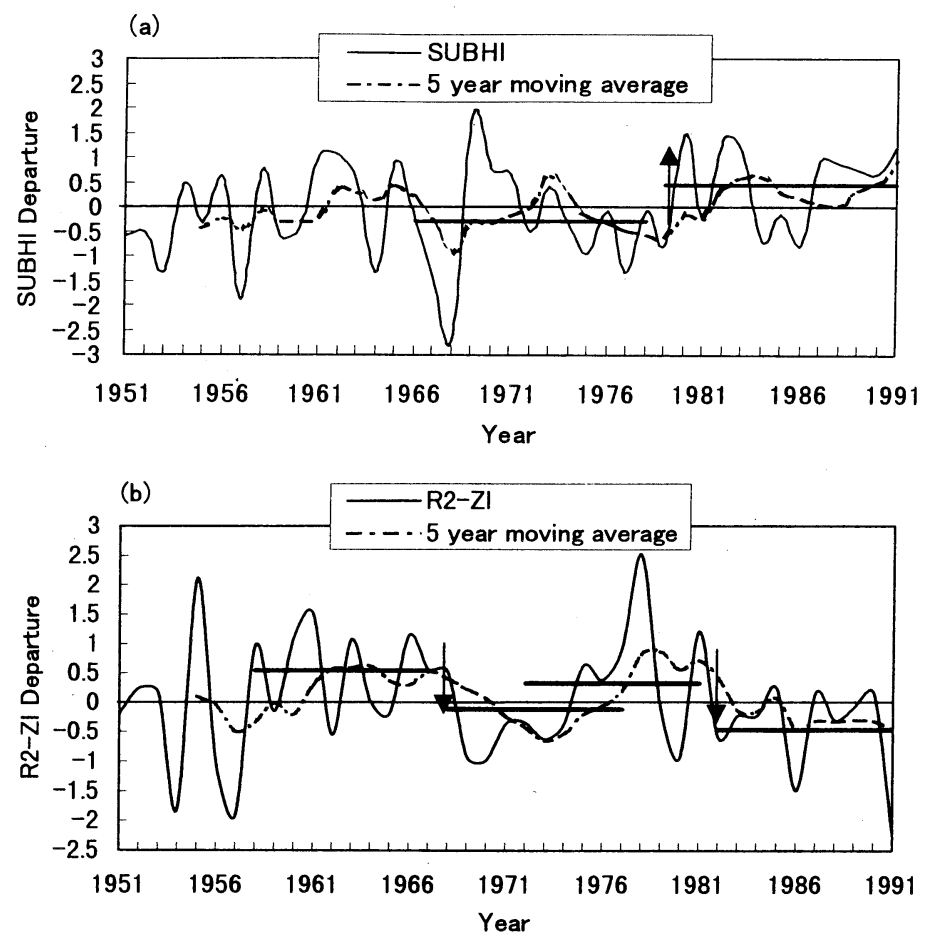

Figure 5. The annual and decadal change for R2-ZI (westerly flow index in the East Asia) in July and SUBHI (subtropical high in the western Pacific Ocean) in May from 1951 to 1991. (a) for R2-ZI in July and (b) for SUBHI in May.

In fact, variations in the summer subtropical high are accompanied by three apparent jumps. The first northward jump of the subtropical high occurs in the middle or last part of June, with the movement of its ridgeline over the region $20-25^{\circ} \mathrm{N}$ and $110-115^{\circ} \mathrm{E}$. In the early and middle part of July, the second northward jump of the ridgeline is assumed and it reaches the position of $25-30^{\circ} \mathrm{N}$. These might be corresponding to the beginning of rainy season in the Yellow River and the ending of rainy season in the Yangtze Valley. The third jump brings the ridgeline of subtropical high over the region around $30^{\circ} \mathrm{N}$, thus leading to the beginning of the rainy season in the northern China and the dry season in the Yangtze Valley (Ding 1994; Si 1989, 1995). Every jump will make the subtropical high move northward and westward. The persistence of the subtropical high in terms of the correlation coefficient of the area index for consecutive months was very clear and the month-to-month correlation coefficients were greater than 0.60 at significant level of 95\% (Ding 1994).

The monthly SUBHI used in this study is different from the subtropical high area index defined by Ding (1994). For example, in June, the ridgeline is located in the regions $\left(20-25^{\circ} \mathrm{N}\right.$, $110-115^{\circ} \mathrm{E}$ ) which is the western part of SUBHI used in this study. That is, the subtropical high in the western Pacific from May to August is persistently moving northward and westward. Therefore, in this study, the SUBHI in May correlated with RAI in the Yangtze Valley will be used as one of the factors to forecast summer rainfall in the Yangtze Valley.

In general, the positive (negative) SUBHI in May and negative (positive) R2-ZI in July strongly corresponds to the occurrence of remarkably wet (dry) condition in the Yangtze Valley.

Taking into consideration the decadal fluctuation of SUBHI in May and R2-ZI in July, it is shown that there are twice obvious decadal changes for the R2-ZI in July and a decadal change for SUBHI in May (see Fig. 5). The first decadal change for the R2-ZI in July occurred in 
Table 4. The decadal fluctuation characteristics of RAI in the Yangtze Valley, standardized departure for SUBHI in May and for R2-ZI in July on the analysis of the Student-t test. Here, SD indicates standardized departure. RAI is rainfall anomaly index

\begin{tabular}{lccccc}
\hline \multicolumn{1}{c}{ Variance } & $\begin{array}{c}\text { Change point } \\
\text { (time) }\end{array}$ & $\begin{array}{c}\text { Span } \mathrm{K} \\
\text { (year) }\end{array}$ & $\mathrm{t}$ & $\begin{array}{c}\text { Confidence } \\
90 \% \mathrm{t} \text {-test }\end{array}$ & $\begin{array}{c}\text { Level } \\
95 \% \mathrm{t} \text {-test }\end{array}$ \\
\hline RAI in Yangtze in JJA & 1978 & 13 & 2.28 & 1.71 & 2.06 \\
SD in SUBHI in May & 1978 & 13 & 1.98 & 1.71 & 2.06 \\
SD in R2-ZI in July & 1967 & 10 & -2.24 & 1.73 & 2.10 \\
& 1981 & 10 & -2.01 & 1.73 & 2.10 \\
\hline
\end{tabular}

the mid 1960s. Its average R2-ZI standardized in July (0.55) in the period 1958-1967 is apparently different form the other R2-ZI $(-0.11)$ in the period 1968-1977. On the other hand, the second decadal change for R2-ZI in July and the decadal change for SUBHI in May occurred in the first of 1980 s and the end of 1970 s, respectively. The average R2-ZI changed from 0.33 in the period $1972-81$ to -0.46 in the period 1982-91 and the average SUBHI standardized in May changed from -0.31 in the period $1966-$ 78 to 0.44 in $1979-1991$. Table 4 shows that summer RAI in the Yangtze Valley is corresponding to the decadal changes for R2-ZI in July and SUBHI in May. It shows that the summer RAI in the Yangtze Valley is not only closely related to annual variability of R2-ZI in July and SUBHI in May but also associated with their decadal change at the end of the 1970s.

Iwasaka et al. (1988) illustrated the better positive correlation between area-averaged SST anomaly in the north and central part of the Pacific Ocean and a $500 \mathrm{hPa}-$ level height field anomaly in East Asia. The descents of SST in the mid-end of $1960 \mathrm{~s}$ and the mid-end of 1970s in the north of Pacific Ocean have been described by Zhang and Levitus (1997). Moreover, the warming changes of SST in the north of the Pacific Ocean from the end of 1960s to the mid 1970s and colder changes in the midend of the 1970s were very significant. The two decadal fluctuations for R2-ZI (westerly flow index) in July are possibly associated with the SST change in the northern Pacific Ocean. The variation of SST in the north of the Pacific Ocean could influence westerly flow at the 500 hPa-level in middle-high latitudes and cause the variation of RAI in the Yangtze Valley.

Nitta and Yamada (1989) discussed that the fluctuation of the atmospheric circulation in the Northern Hemisphere at the end of the 1970s was possibly due to a modification in the equatorial sea surface temperature (SST). Bjerknes (1969) clearly explained the relationship between Hadly circulation and Walker circulation. At the end of the 1970s, the marked increasing for SUBHI in May is possibly associated with the variation of atmospheric circulation in the Northern Hemisphere. Shinoda et al. (1986) analyzed the global simultaneity of abrupt seasonal change in precipitation which occurred in May and June of 1979 and mentioned abrupt change occurring in equatorial East Africa from the first stage (the first 10-day period of May) to second stage (the first 10-day period of June). Moreover, there was an abrupt change in the structure of the Baiu front over the China continent in late May of 1979 (Kato 1985). It is not clear whether the decadal change for RAI in the Yangtze Valley at the end of 1970 s is associated with the global simultaneous abrupt change for precipitation in 1979. However, there are several associations for atmospheric circulation and rainfall in different regions in tropical lower latitudes. Murakami et al. (1984) considered that the evaporation over the Arabian Sea constitutes the key contribution to the moisture supply for summer monsoon rains in 1979. Kanamitsu and Krishnamurti (1978) show this to be true for Africa during the continental drought year of 1972 (stronger Hadley-type over-turnings) as compared with the wetter year of 1967 (stronger Walker-type over-turnings). In 1972, strong ascending motion in equatorial region was compensated by increased subsidence in the subtropics of both hemispheres. Nicholson (1986) suggested that the common factors which influence rainfall through most of Africa 
include the Hadley circulation and the tropical easterly flow and showed that different regional rainfalls in African have different characteristics. The interaction between tropical and extratropical flow is very complex and inconclusive. In this study, we only can say, the decadal change of RAI in the Yangtze Valley in the end of $1970 \mathrm{~s}$ is related to the variation of the SUBHI $\left(20-30^{\circ} \mathrm{N}, 130-170^{\circ} \mathrm{E}\right)$ in May. In general, the variation of subtropical high in the western Pacific is directly associated with Hadley circulation and the Intertropical Convergence Zone (ITCZ), and the anomalous excursions of the ITCZ and Hadley circulation are related to African rainfall variability (e.g. Kraus 1977; Kanamitsu and Krishnamurti 1978). However, the impact of the Hadley circulation on the subtropical high in the western Pacific Ocean by associating with the adjustment of Walker, ITCZ and tropical easterly flow would be further investigated. In fact, to discuss the relationship between summer rainfall in the Yangtze Valley and that for several regions in Africa is significant, although it is very complex.

\section{Results and Discussion}

Rainfall Anomaly Index (RAI) in the Yangtze Valley is negatively correlated with RAI in the middle reaches of the Yellow River. Furthermore, the analysis shows that summer rainfalls in two regions for the period 1951-57 and 1958-91 have different correlation characteristics. The summer rainfall in the Yangtze Valley and the middle reaches of the Yellow River in the period $1951-57$ is consistent. For the period 1958-91, there is apparently negative correlation. Using the moving average for 3-year, 5year, 7 -year, 9-year and 11-year, we found that the negative correlation of RAI in between the two regions is rapidly weakened by the over 5year moving averages. It indicates that shortterm fluctuation of summer rainfall contributing negative correlation in the two regions is very important.

The RAI in the middle reaches of the Yellow River during El Niño year corresponds to dry conditions. Analyzing the correlation of monthly SST in the tropical western Pacific
Ocean with the summer RAI in the Yangtze Valley in the period 1978-1991, it is found that the summer RAI in the Yangtze Valley is closely related to the SST in June in the tropical western Pacific Ocean. For instance, during the onset of El Niño, wet conditions occurred in 1982, 1983, 1987 and 1991 and dry conditions occurred in 1988 (La Niña) for the Yangtze Valley. Recently, Simmon et al. (1996) obtained that there were significantly positive association between interannual variation of summer rainfall in the lower reaches of the Yangtze Valley and SST in the $10-20^{\circ} \mathrm{N}, 120-130^{\circ} \mathrm{E}$ Marsden square which is located in the west part of our study region (EQ- $\left.14^{\circ} \mathrm{N}, 130-150^{\circ} \mathrm{E}\right)$. It indicates that summer SST in the two regions is very important for summer rainfall in the Yangtze Valley since the end of 1970s and it is associated with wet conditions in the region during the onset of El Niño year.

The RAI in the Yangtze Valley associated with atmospheric circulation show that R2-ZI (westerly flow index in East Asia) in July and SUBHI (subtropical high in the western Pacific Ocean) in May are two important factors influencing the summer RAI in the Yangtze Valley. The correlation between summer (June, July and August) SUBHI in the $20-30^{\circ} \mathrm{N}, 130$ $170^{\circ} \mathrm{E}$ and RAI in the Yangtze Valley cannot reach the significant level because the subtropical high impacting on summer rainfall in eastern China is moving in summer. It corresponds to the analysis by Ding (1994) who considered the subtropical high in the western Pacific Ocean associated with summer rainfall in eastern China is persistently moving northward and westward. In summer (June, July and August), the subtropical high impacting on summer rainfall in the Yangtze Valley has moved on the west part of the SUBHI $\left(20-30^{\circ} \mathrm{N}\right.$, $130-170^{\circ} \mathrm{E}$ ) in our study. The correlation analysis that the SUBHI in May in our study is closely associated with the summer subtropical high which influences summer rainfall in the Yangtze Valley.

On the analysis of decadal changes for R2-ZI in July and SUBHI in May, it is shown that the decadal change of RAI in the Yangtze Valley in the end of $1970 \mathrm{~s}$ are corresponding to the decadal changes of R2-ZI in July and SUBHI in 
May. Although the first decadal change for R2ZI in July occurred in the end of the 1960s, it did not cause large change for the RAI in the Yangtze Valley. The reason for this is possibly due to the average SUBHI which is lower than the normal from the mid-1960s to the end of the 1970s. As we know, RAI in the Yangtze Valley is positively correlated with SUBHI in May. The descent of SUBHI in May from the mid 1960 s to the end of the 1970 s cause summer rainfall to decrease in the Yangtze Valley. However, by the end of the $1970 \mathrm{~s}$, the decadal change pattern for R2-ZI in July and SUBHI in May is benefiting from the ascent of summer rainfall in the Yangtze Valley. For example, the ascent of SUBHI in May and descent of R2-ZI in July from the end of the 1970 s and the first years of the 1980s made average summer rainfall in the period 1979-91 in the Yangtze Valley increase.

\section{Acknowledgments}

Thanks are due to Prof. G.-W. Si for helpful discussions and comments, and Dr. E.R. Ranatunge for beneficial suggestions and a lot of help.

(Received Mar. 18, 1997)

(Accepted Mar. 28, 1998)

\section{References}

Bjerknes, J. 1969. Atmosphere teleconnection from the equatorial Pacific. Mon. Wea. Rev. 97: 163172.

Buell, C. E. 1975. The topography of empirical orthogonal functions. Preprints Fourth Conf. on Prob. and Stats, in Atmos. Sci. Tallahassee, FL, Amer. Meteor. Soc. 188.

Buell, C. E. 1979. On the physical interpretation of empirical orthogonal functions. Preprints Sixth Conf. on Prob. and Stats. in Atmos. Sci. Bauff. Alta., Amer. Meteor. Soc. 112.

Chen, L.-X., Dong, M., and Shao, Y.-N. 1992. The characteristics of interannual variation on the East Asian monsoon. J. Meteor. Soc. Japan 70: 397-421.

Ding, Y. H. 1994. Monsoon over China. Dordrecht ed. Kluwer Academic Publishers.

Ding, Y. H. 1992. Summer monsoon rainfall in China. J. Meteor. Soc. Japan 70: 371-396.

Ehrendorfer, M. 1987. A regionalization of Austria's precipitation climate using principle component analysis. J. Climatol. 7: 71-89.

Fu, C., Diaz, H. F. and Fletcher, J. O. 1986. Characteristics of the response of sea surface temperature in the Central Pacific associated with warm episodes of the Southern Oscillation. Mon. Wea. Rev.
114: $1716-1738$.

Guetter, A. K. 1996. Are the El Niño and La Niña predictors of Iowa river seasonal flow? J. Appl. Meteor. 25: 690-705.

Guo, Q.-Y. 1988. An analysis of East Asian monsoon index and its variation. Acta Geographica Sinica 38: 207-217 (in Chinese)

Horel, J. 1984. Complex principle component analysis: Theory and example. J. Climate Appl. Meteor. 23: 1660-1673.

Iwasaka, N., Hanawa, K., and Toba, Y., 1988. Partition of the north Pacific Ocean based on similarity in temporal variations of the SST anomaly. $J$. Meteor. Soc. Japan 66: 433-443.

Iyengar, R. N., and Basak, P. 1994. Regionalization of Indian Monsoon Rainfall and Long-term Variability Signals. Int. J. Climatol. 14: 1095-1114.

Japan Meteorological Agency. 1991. Monthly Report on Climate System. No. 91: 1-12.

Japan Meteorological Agency. 1992. Monthly Report on Climate System. No. 92: 1-12.

Kanamitsu, M., and Krishnamurti, T. N. 1978. Northern summer tropical circulations during drought and normal rainfall months. Mon. Wea. Rev. 106: 331-347.

Karl, T. R., and Riebsame, W. E. 1984. The indentification of 10 - to 20 -year temperature and precipitation fluctuation in contiguous United States. $J$. Climate Appl. Meteor. 23: 950-966.

Kato, K. 1985. On the abrupt change in the structure of the Baiu front over the China continent in late May of 1979. J. Meteor. Soc. Japan 63: 20-36.

Katz, R. W., and Glantz, M.H. 1986. Anatomy of a rainfall index. Mon. Wea. Rev. 114: 764-771.

Kraus, E. B. 1977. Subtropical droughts and crossequatorial energy transport. Mon. Wea. Rev. 105: 1009-1018.

Kulkarni, A., Kripalini, R. H., and Singh, S. V. 1992. Classification of summer monsoon rainfall patterns over India. Int. J. Climatol. 12: 269-280.

Mills, G. F., Lana, X., and Serra, C. 1994. Catalonian precipitation patterns principal component analysis and automated regionalization. Theor. Appl. Climatol. 49: 201-212.

Mills, G.F. 1995. Principal Component analysis of precipitation and rainfall regionalization in Spain. Theor. Appl. Climatol. 50: 169-183.

Murakami, T., Nakazawa, T., and He, J. 1984. On the 40-50 day oscillation during the 1979 northern hemisphere summer, Part II: heat and moisture budget. J. Meteor. Soc. Japan 62: 469-484.

Nicholson, S. E. 1986. The spatial coherence of African rainfall anomalies: interhemispheric teleconnection. J. Clim. Appl. Meteor. 25: 1365-1379.

Nitta, T., and Yamada, S. 1989. Recent warming of tropical sea surface temperature and its relationship to the Northern hemisphere circulation. J. Meteor. Soc. Japan 67: 375-383.

Nitta, T., and Hu, Z. Z. 1996. Summer climate variabil- 
ity in China and its association with $500 \mathrm{hPa}$ height and tropical convection. J. Meteor. Soc. Japan 74: 425-445.

Quinn, W. H., Neal, V. T., and Autunez de Mayolo, S. E. 1987. El Niño occurrence over the four and a half centuries. J. Geophys. Res. 92: 14449-14461.

Richman, M. B. 1981. Obliquely rotated principal components: An improved meteorological map typing technique? J. Appl. Meteor. 20: 11451159.

Richman, M. B. 1986. Rotation of principal components. J. Climatol. 6: 293-335.

Shinoda, M., Mikami, T., Iwasaki, K., Kitajima, H., Eguchi, T., and Masuda, K. 1986. Global simultaneity of the abrupt seasonal changes in precipitation during May and June of 1979. J. Meteor. Soc. Japan 64: 531-564.

Si, G.-W. 1989. On the large-scale circulation of mei-yu system over East Asia. Acta Meteor. Sinica 47: 312-323 (in Chinese).

Si, G.-W., Kato, K., and Takeda, T. 1995. The early summer seasonal change of large-scale circulation over East Asia and its relation to change of the frontal feature and frontal rainfall environment during 1991 summer. Adv. Atmos. Sci. 12: 151-176.

Simmonds, I., Bi, D.-H., and Yan, B. L. 1996. Relationships between summer rainfall over China and ocean temperatures in the western Pacific. $J$. Meteor. Soc. Japan 74: 273-279.

Tian, S.-F., and Yasunari, T. 1992. Time and space structure of interannual variations in summer rainfall over China. J. Meteor. Soc. Japan 70: 585-
596.

Wang, S.-W., and Zhao, Z.-C. 1981. Droughts and floods in China, 1470-1979. In Climate and History, ed. Wigley, Ingran and Farmer., 271-288. Cambridge.

Wang, S.-W. 1994. Introduction of climate system. Beijing: Meteorology Press. (in Chinese)

Wang, W.-C., and Li, K. 1990. Precipitation fluctuation over semiarid region in northern China and the relationship E1 Niño/southern oscillation. J. Climate 3: 769-783.

Wei, F. Y., and Chao, H. X. 1995. Detection of abrupt change and trend prediction of air temperature in China, the Northern hemisphere and global. Chinese J. Atmos. Sci. 19: 83-90.

Yatagai, A., and Yasunari, T. 1994. Trends and decadal-scale fluctuations of surface air temperature and precipitation over China and Mongolia during the recent 40 year period (1951-1990). J. Meteor. Soc. Japan 72: 937-957.

Yatagai, A., and Yasunari, T. 1995. Interannual variations of summer precipitation in the arid/semiarid regions in China and Mongolia: Their regionality and relation to the Asian summer monsoon. J. Meteor. Soc. Japan 73: 909-923.

Zhang, L., Qiao, Q.-M., Deng, B., and Zhang, X. 1986. Large-scale compositing analysis and model of the Meiyu (Baiu) front. Scientia Atmospherica Sinica, Special Issue 191-201.

Zhang, R.-H., and Levitus, S. 1997. Structure and cycle of decadal variability of upperocean temperature in the north Pacific. J. Climate 10: 710-727. 